\title{
Risk of severe life threatening asthma and $\beta$ agonist type: an example of confounding by severity
}

\author{
J E Garrett, S F Lanes, J Kolbe, H H Rea
}

\begin{abstract}
Background - A study was undertaken to test the hypothesis that a particular inhaled $\beta$ agonist, fenoterol, increases the incidence of severe life threatening asthma.
\end{abstract}

Methods - A retrospective cohort was assembled comprising 655 patients with asthma aged 15-55 years who attended a single Auckland hospital for acute asthma between 1 January 1986 and 31 December 1987 (the "index event"). Patients were followed for the occurrence of death from asthma or admission to the intensive care unit for asthma, until death or 31 May 1989. Data on asthma medications and asthma severity were obtained from forms used specifically for managing patients with acute asthma in the emergency department and maintained as part of the hospital record and/or from the hospital record (when patients were admitted).

Results - Following the index event 90 admissions to the intensive care unit (ICU) and 15 asthma deaths were identified. Before adjusting for asthma severity, patients using inhaled fenoterol had a greater incidence of severe life threatening asthma than patients using inhaled salbutamol $(R R=2.1,95 \%$ CI 1.4 to 3.1). After controlling for two markers of severe asthma used in previous studies - a hospital admission in the previous year and prescribed oral corticosteroids - the relative risk estimate declined to 1.5 (95\% CI 1.0 to 2.3). After controlling further for the number of hospital admissions during the study period, continuous oral corticosteroid use rather than short courses of treatment, severity of the previous attack requiring a hospital visit, and race, fenoterol was not associated with severe life threatening asthma at the time of attendance for a previous hospital visit $\left(\mathbf{R R}=1.0,95 \%\right.$ CI 0.6 ${ }^{\wedge}$ to 1.7$)$.

Conclusion - Fenoterol is used more often by patients with severe asthma and, after adjusting for differences in baseline risk, it does not increase the risk of severe life threatening asthma.

(Thorax 1996;51:1093-1099)

Keywords: severe life threatening asthma, fenoterol, confounding by severity.

Received 10 February 1995

Returned to authors

5 June 1995

5 June 1995
Revised version received

Revised version received

22 September 1995

Accepted for publicat
Fenoterol, a $\beta$ agonist used to treat acute asthma, was introduced in New Zealand in
1976. In 1989 a case-control study from Wellington reported that fenoterol was associated with an increased risk of death from asthma. ${ }^{1}$ Fenoterol $(200 \mu \mathrm{g} /$ puff) was the newest $\beta$ agonist on the market and was introduced as a drug with a longer duration of action than the then most popular drug, salbutamol $(100 \mu \mathrm{g} /$ puff $)$. If fenoterol was prescribed preferentially to patients whose asthma was not controlled with existing medications, and baseline risk was not adequately measured and controlled in an epidemiological study, fenoterol would appear to be associated with a poor prognosis even if it were as safe and effective as other inhaled $\beta$ agonists. A small amount of bias due to confounding by asthma severity was demonstrated in a previous study conducted in Wellington in which adjustment for two markers of severity (a hospital admission in the previous year and a prescription for oral steroids at the time of a previous hospital admission) reduced the relative risk (RR) estimate for death associated with inhaled fenoterol from 2.7 to $2.3 .^{23}$ More recently, a study of asthma death and near death conducted in Saskatchewan, Canada also showed that adjustment for recent hospital admissions and any use of oral steroids reduced the estimate of the rate difference for fenoterol by $36 \%$, from $56.3 / 10000$ personyears to $36.2 / 10000$ person-years. ${ }^{4}$ In both the Wellington and Saskatchewan studies, therefore, adjustment for two markers of asthma severity reduced the magnitude of the association between fenoterol and asthma death. Debate has focused on whether or not residual confounding could explain the association. ${ }^{25-8}$

To help determine whether fenoterol increases the risk of life threatening asthma or whether the association can be explained by preferential prescribing of fenoterol to patients with severe asthma we conducted a retrospective cohort study for which data on drug use and asthma severity were obtained in greater completeness and detail than was available in previous studies.

In characterising severity by use of oral corticosteroids, previous studies ${ }^{12410}$ made no distinction between patients who receive a short course of oral corticosteroids in response to an acute exacerbation and those with chronically severe asthma who require continuous oral corticosteroids. In addition, measures of acute severity at the time of the patient's previous hospital admission were often not recorded within the hospital records. We wondered what the effect would be of measuring and controlling for these variables. 


\section{Methods}

In 1986 a system was introduced at Middlemore Hospital in South Auckland (population 310000 ) whereby Emergency Department medical staff assessed and managed patients with asthma according to a protocol stipulating that certain data on medications and severity be recorded on a specially designed triplicated form. These forms and regular hospital records were used to identify all residents of South Auckland aged 15-55 years who presented to the emergency department with an attack of asthma between 1 January 1986 and 31 December 1987, whether they required admission or not (the "index event"; fig 1). Older patients were excluded because of a greater likelihood that their drugs were prescribed for conditions other than asthma - for example, chronic obstructive pulmonary disease - and younger patients were excluded because they would have been admitted to a paediatric hospital in central Auckland.

Patients were followed for the occurrence of a severe life threatening attack which we defined as an admission to the intensive care unit for asthma or asthma death, until death or 31 May 1989 (the approximate date of publication of the first case-control study on fenoterol), whichever came first. Patients admitted to an intensive care unit in Auckland with asthma are seriously ill, with a mean $\mathrm{pH}$ of 7.1 and a mean $\mathrm{PaCO}_{2}$ of $10 \mathrm{kPa} .{ }^{11}$ Other hospital admissions or visits to the emergency department for asthma were also identified as they provided information on severity markers and drug use. In every instance patients presenting at hospital for asthma in South Auckland are assessed in the emergency department before a decision is made regarding need for admission. Use of the emergency department was assessed by searching the records at the hospital from which patients were recruited. Computer files of the National Health Statistics Centre (and the locally maintained database) were used to validate regional hospital admissions and to identify any admissions outside the region and deaths. Admissions to the intensive care unit were identified using computer records of the two regional units and these files were checked against paper records.

Information on the use of asthma drugs and disease severity was obtained from hospital records for each hospital visit. Patients were

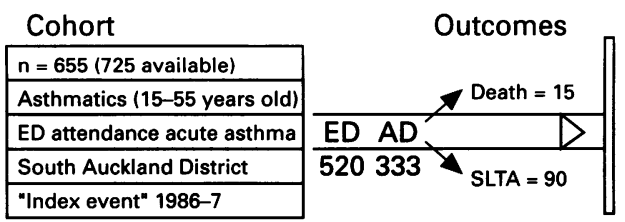

April 1989

Figure 1 Model of retrospective cohort study design. $E D=$ Emergency Department; $A D=$ non-intensive care unit admission; SLTA = severe life threatening asthma attack. Drug information and indices of severity were derived from discharge medications and clinical evaluation at the time of the previous attack. Incidence rates for severe life threatening asthma and death were calculated as the number of events divided by person time from the the number of events divided by person time from the
index event until death or the end of the study (April 1989). characterised according to asthma medications at admission and discharge, age, race, sex, current smoking, physician assessment of overall asthma severity (mild, moderate, severe), frequency of usual symptoms (occasional, most weeks, most days), and number of prior hospital visits by visit type (in the year prior to the index visit and subsequently) as follows: emergency department visits $(0,1,2-3,4+)$, prior hospital admissions $(0,1,2+)$, and prior admission to intensive care unit $(0,1,2+)$. The presence and number of prior hospital visits in the past year and past six months, physician assessment of compliance and psychosocial factors (psychiatric diagnosis, requiring psychotropic therapy, self discharge, recent bereavement, unemployment, and drug addiction), and clinical data on the severity of the acute attack were also considered. Measures of acute severity at each hospital visit include an ability to speak at presentation (sentences, words, none), respiratory rate ( $<10$ breaths/ min, 10-19, 20-29, 30-39, 40+), level of consciousness (normal/altered), need for mechanical ventilation, arterial blood $\mathrm{pH}$ and $\mathrm{PaCO}_{2}$ on presentation, physician assessment of severity (mild, moderate, severe), and the ratio of peak expiratory flow rate (PEF) on admission to PEF at discharge $(<36 \%, 36-54 \%,>55 \%)$ (PEF was calculated in this manner since height was not available and thus results could not be expressed as percentage predicted).

Person time was accrued from the discharge date for the index hospital visit until death or end of study. Each patient was classified according to demographic data, asthma drugs, and indices of acute and chronic severity at the time of the index hospital visit. Patients were reclassified for any subsequent hospital visits. Thus, patients were classified according to asthma drugs prescribed and the severity of their asthma at the time of discharge from their previous hospital visit until a subsequent hospital visit or until the end of follow up. The only exception was for the use of oral corticosteroids which was characterised at the time of admission at the previous hospital attendance (as it was in previous studies). To avoid adjusting for a possible adverse effect of fenoterol after admission to hospital, asthma severity was classified at the time of the previous hospital visit, and not at the outcome event. This allowed control for baseline risk and allowed for the measurement of the subsequent effect of fenoterol.

Incidence rates for severe life threatening asthma were computed as the total number of events divided by the person time contributed by each subject from the index event until the date of death or the end of the follow up period on 31 May 1989. Rates of severe life threatening asthma were computed according to the type of $\beta$ agonist(s) used. To measure the effect of fenoterol, RR estimates were calculated comparing users of inhaled fenoterol with users of inhaled salbutamol as this was the method of comparison used in the Wellington studies. ${ }^{12910}$ Excluded from this analysis were those using salbutamol and fenoterol concomitantly, users of other $\beta$ agonists, and non-users of $\beta$ agonists. 
Finally, a comparison was made of users of two dose formulations of fenoterol by metered dose inhaler: $200 \mu \mathrm{g}$ fenoterol/inhalation (Berotec), and $100 \mu \mathrm{g}$ fenoterol plus $40 \mu \mathrm{g}$ ipratropium/ inhalation (Duovent).

Each drug, demographic variable, and severity marker was considered as a potential confounding variable. Variables that were predictive of the risk of severe life threatening asthma were identified among people unexposed to fenoterol, then $R R$ estimates were computed adjusting for each of these variables individually. ${ }^{12}$ The variables that resulted in the greatest change in the $R R$ estimate were included in various combinations in both stratified analyses and Poisson regression models. ${ }^{12}$ The number of terms in the multivariate models was limited when corresponding stratified analyses revealed sparse data. ${ }^{13}$ Logistic regression was used to examine the odds of being prescribed fenoterol among patients of different severity, and the width of the $95 \%$ confidence intervals was used to assess the precision of the effect estimates. ${ }^{12}$

All of the data for this study were recorded before the publication of the first report of an association between fenoterol and asthma death. The research assistants performing the data extraction were blinded as to the precise hypothesis under study.

\section{Results}

\section{PATIENT CHARACTERISTICS}

A total of 655 patients with asthma were identified who fulfilled the entry criteria (a further 51 patients resided outside South Auckland and in 19 patients the data were not sufficiently complete to be recruited (demographic data missing or triplicated emergency department form not used)). These 655 subjects contributed 1571 person years to the analysis. The distribution of the study population at entry according to age, sex, race, and type of index event was similar to data from a prospective study on emergency department care at Middlemore Hospital ${ }^{14}{ }^{15}$; the population was young ( $56 \%$ of patients less than 30 years of age) and predominantly female $(64 \%)$. The racial distribution was $44 \%$ European, 29\% Pacific Islander, 26\% Maori, and $1 \%$ were classified as "other" or for whom information on race was missing. Most of the index events (59\%) were visits to the emergency department, while the remainder were hospital admissions including $47(7 \%)$ to the intensive care unit.

There were 105 subsequent severe life threatening attacks among 66 patients comprising 90 admissions to the intensive care unit and 15 asthma deaths. Four of the deaths occurred shortly after admission (two were receiving cardiopulmonary resuscitation on arrival). Independent of these severe life threatening attacks, there were 333 other hospital admissions and 520 emergency department visits not requiring admission (fig 1).

DRUG THERAPY

The distribution of patients according to asthma drugs used at any time during the study
Table 1 Distribution of subjects by asthma drug use during study at time of discharge

\begin{tabular}{lcc}
\hline Drug & $\begin{array}{l}\text { Subjects } \\
(n=655)\end{array}$ & $\%$ \\
\hline Inhaled $\beta$ agonists & & \\
$\quad$ Any & 624 & 95 \\
Salbutamol $\dagger$ & 455 & 70 \\
$\quad$ Fenoterol $\dagger$ & 176 & 27 \\
$\quad$ Fenoterol and ipratropium $\dagger$ & 62 & 10 \\
Ipratropium & 11 & 2 \\
Oral $\beta$ agonists & 80 & 12 \\
Theophylline & 493 & 75 \\
Sodium cromoglycate & 43 & 7 \\
Inhaled corticosteroids & 410 & 63 \\
$\quad$ Any & 266 & 41 \\
<1 mg/day & 146 & 22 \\
>1 mg/day & 443 & 68 \\
Oral corticosteroids* & 44 & 7 \\
$\quad$ Any & 427 & 65 \\
$\quad$ Continuous course & \\
\hline
\end{tabular}

† Excludes users of concomitant inhaled fenoterol and inhaled salbutamol.

"Recorded at time of attendance of "previous event" rather than discharge.

is shown in table 1 . Only 18 patients used $\beta$ agonists by nebuliser, so this mode of administration was grouped with metered dose inhalers (MDIs) and powdered formulations as inhaled $\beta$ agonists. (This decision did not substantially alter the results obtained).

Table 2 shows the unadjusted baseline RR estimates for the main severity markers that were associated with severe life threatening asthma among non-users of fenoterol. The strongest predictors of severe life threatening asthma were use of at least three classes of asthma medications (inhaled $\beta$ agonists, oral $\beta$ agonists or theophylline, disodium cromoglycate, inhaled corticosteroids, oral corticosteroids) $(R R=31)$, continuous use of oral corticosteroids $(R R=24)$, inability to speak at the previous hospital visit $(R R=19)$, multiple hospital admissions $(R R=18)$, symptoms on most days $(R R=16)$, and a hospital admission in the previous six months $(R R=11)$. Each of these associations was strong but imprecise. For example, use of at least three classes of asthma drugs has the largest RR estimate, but only one case of severe life threatening asthma was not using at least three kinds of asthma drugs and the confidence interval is extremely wide (95\% CI 6 to 629 ).

To introduce confounding bias, severity markers must be associated not only with the risk of severe life threatening asthma but also with the type of $\beta_{2}$ agonist prescribed. Table 3 shows the odds ratios for prescribing fenoterol in relation to the number of prior hospital admissions and the type of course of oral corticosteroids. The odds ratio for receiving fenoterol among patients with multiple admissions during the study relative to patients with no prior admissions is 2.9 (95\% CI 2.4 to 3.5).The odds ratio for receiving fenoterol among patients on continuous oral corticosteroids relative to patients who did not receive oral corticosteroids following a hospital visit is 1.9 (95\% CI 1.2 to 2.8 ).

CONTROLLING FOR SEVERITY

Table 4 shows RR estimates for severe life threatening asthma comparing users of inhaled 
Table 2 Baseline rate estimatest for severe life threatening asthma and mortality for selected severity markers at time of previous visit

\begin{tabular}{|c|c|c|c|c|c|}
\hline Severity marker & $\begin{array}{l}\text { SLTAI } \\
\text { Death }\end{array}$ & $\begin{array}{l}\text { Person } \\
\text { years }\end{array}$ & $\begin{array}{l}\text { Missing } \\
\text { person } \\
\text { years (\%) }\end{array}$ & $R R$ & $(95 \% C I)$ \\
\hline \multicolumn{6}{|l|}{$\begin{array}{l}\text { Severity of previous attack: } \\
\text { Ability to speak (vs short } \\
\text { sentences/normal) }\end{array}$} \\
\hline $\begin{array}{l}\text { None } \\
\text { Some }\end{array}$ & $\begin{array}{l}14 \\
18\end{array}$ & $\begin{array}{r}84 \\
211\end{array}$ & $\begin{array}{l}26 \\
26\end{array}$ & $\begin{array}{r}18.6 \\
9.5\end{array}$ & $\begin{array}{l}(6.4 \text { to } 65.5) \\
(3.4 \text { to } 32.8)\end{array}$ \\
\hline $\begin{array}{l}\text { Physician assessment of severity } \\
\text { (vs. mild/moderate) }\end{array}$ & & & & & \\
\hline Severe & 30 & 207 & 20 & 8.0 & $(4.1$ to 16.6$)$ \\
\hline Peak flow ratio (initial/discharge) & & & & & \\
\hline $\begin{array}{l}<0.36 \\
0.36-0.54\end{array}$ & $\begin{array}{l}29 \\
10\end{array}$ & $\begin{array}{l}245 \\
282\end{array}$ & & $\begin{array}{l}7.0 \\
2.1\end{array}$ & $\begin{array}{l}(2.9 \text { to } 20.3) \\
(0.7 \text { to } 6.8)\end{array}$ \\
\hline Mechanical ventilation & 3 & 12 & 3 & 5.4 & $(1.3$ to 15.5$)$ \\
\hline Altered consciousness & 10 & 48 & 2 & 5.0 & (2.4 to 9.8$)$ \\
\hline \multicolumn{6}{|l|}{$\begin{array}{l}\text { Morbidity: } \\
\text { Prior asthma admissions during } \\
\text { study (vs none) }\end{array}$} \\
\hline $\begin{array}{l}2+ \\
1 \\
\text { Any previous } 6 \text { months } \\
\text { Any previous year }\end{array}$ & $\begin{array}{l}24 \\
18 \\
31 \\
35\end{array}$ & $\begin{array}{l}100 \\
368 \\
137 \\
238\end{array}$ & $\begin{array}{l}0 \\
0 \\
0 \\
0\end{array}$ & $\begin{array}{r}17.8 \\
3.6 \\
10.7 \\
7.9\end{array}$ & $\begin{array}{l}(7.9 \text { to } 65.5) \\
(1.5 \text { to } 9.3) \\
(6.0 \text { to } 19.5) \\
(4.3 \text { to } 15.1)\end{array}$ \\
\hline $\begin{array}{l}\text { Chronic severity: } \\
\text { Symptoms most days/weeks } \\
\text { (vs occasional) }\end{array}$ & 28 & 416 & 38 & 15.7 & (3.0 to 324.5 ) \\
\hline $\begin{array}{l}\text { Medications: } \\
\text { Use of } 3 \text { or more asthma drug } \\
\text { classes } \\
\text { Oral steroid course }\end{array}$ & 48 & 600 & 0 & 30.9 & ( 6.0 to 629.1 ) \\
\hline $\begin{array}{l}\text { Continuous } \\
\text { Tapering }\end{array}$ & $\begin{array}{l}8 \\
7\end{array}$ & $\begin{array}{l}25 \\
38\end{array}$ & $\begin{array}{l}5 \\
5\end{array}$ & $\begin{array}{l}23.5 \\
13.4\end{array}$ & $\begin{array}{l}(8.0 \text { to } 72.6) \\
(4.3 \text { to } 42.3)\end{array}$ \\
\hline $\begin{array}{l}\text { Demographic: } \\
\text { Maori } \\
\text { Female }\end{array}$ & $\begin{array}{l}29 \\
38\end{array}$ & $\begin{array}{l}273 \\
642\end{array}$ & $\begin{array}{c}0.1 \\
0\end{array}$ & $\begin{array}{l}3.8 \\
1.8\end{array}$ & $\begin{array}{l}(2.1 \text { to } 6.8) \\
(1.0 \text { to } 3.8)\end{array}$ \\
\hline $\begin{array}{l}\text { Psychosocial: } \\
\text { Poor compliance } \\
\text { Psychosocial factors }\end{array}$ & $\begin{array}{l}19 \\
28\end{array}$ & $\begin{array}{l}232 \\
432\end{array}$ & $\begin{array}{l}76 \\
57\end{array}$ & $\begin{array}{l}2.1 \\
1.0\end{array}$ & $\begin{array}{l}(1.1 \text { to } 3.6)^{*} \\
(0.5 \text { to } 1.8)^{*}\end{array}$ \\
\hline
\end{tabular}

SLTA $=$ severe life threatening asthma; $R R=$ rate ratio; $C I=$ confidence interval

† Computed among subjects not exposed to inhaled fenoterol.

* Unable to calculate accurately since not part of emergency department coding form.

Table 3 Relationship between severity and prescribed fenoterol at discharge

\begin{tabular}{ll}
\hline Variable & Odds ratio (95\% CI) \\
\hline Prior admissions & \\
$2+$ (during study period) & $2.9(2.37$ to 3.53$)$ \\
1 (in previous year) & $1.7(1.39$ to 2.06$)$ \\
$\begin{array}{l}\text { Oral corticosteroids at time of } \\
\text { previous attendance }\end{array}$ & \\
$\quad$ Continuous & $1.9(1.23$ to 2.79$)$ \\
Tapering & $1.3(1.06$ to 1.55$)$ \\
\hline
\end{tabular}

fenoterol with users of inhaled salbutamol implementing progressively greater control for baseline risk factors. The unadjusted RR estimate comparing inhaled fenoterol with inhaled salbutamol is 2.1 ( $95 \%$ CI 1.4 to 3.1 ). After adjusting for an admission in the past year and any use of oral corticosteroids (the severity markers used in the Wellington study ${ }^{3}$ ) the RR estimate declines to 1.5 (95\% CI 1.0 to 2.3). When these severity markers are extended to take into account the number of hospital admissions during the period of the

Table 4 Rate ratio ( $R R$ ) estimates for severe life threatening asthma (SLTA) and death comparing inhaled fenoterol with inhaled salbutamol

\begin{tabular}{|c|c|c|}
\hline \multirow[t]{2}{*}{ Factors controlled } & \multicolumn{2}{|c|}{ SLTA/death } \\
\hline & $R R$ & $(95 \% C I)$ \\
\hline None & 2.1 & (1.37 to 3.13 ) \\
\hline $\begin{array}{l}\text { Admission in past year and any oral steroid use at } \\
\text { previous hospital attendance }\end{array}$ & 1.5 & (0.99 to 2.26$)$ \\
\hline $\begin{array}{l}\text { Number of prior admissions during study period and } \\
\text { continuous oral steroid use at previous hospital } \\
\text { attendance }\end{array}$ & 1.3 & $(0.82$ to 1.91$)$ \\
\hline $\begin{array}{l}\text { Number of prior admissions during study period, race, } \\
\text { and continuous steroid use and inability to speak at } \\
\text { previous hospital attendance }\end{array}$ & 1.0 & (0.63 to 1.73$)$ \\
\hline
\end{tabular}

study (as opposed to any versus none), and continuous use of oral corticosteroids (as opposed to any use), the RR estimate decreases further to $1.3(95 \% \mathrm{CI} 0.8$ to 1.9$)$. Finally, after controlling for number of hospital admissions during the study period, continuous use of oral corticosteroids, inability to speak at the previous hospital visit, and race, the RR estimate is $1.0(95 \% \mathrm{CI} 0.6$ to 1.7$)$. The rationale in constructing this model is that admission in the past year and any oral steroid course have been reported previously as good severity markers and were also found to be consistently important in a range of sensitivity analyses that we conducted using different combinations of confounding variables. Inability to speak was selected because of its strong association with severe life threatening asthma and because there were limited missing data compared with other severity markers $(24 \%$ person time was excluded due to missing data), and race was included because, unlike other variables, controlling for this factor tended to increase the $\mathrm{RR}$ for fenoterol. Therefore, by choosing these four risk factors we have utilised the best measurements of acute severity (inability to speak), chronic severity (continuous steroid use), morbidity (previous hospital admissions), and sociodemographic characteristics (race).

Controlling individually for each variable from table 2 revealed that, when comparing users of inhaled fenoterol with those of inhaled salbutamol, control for nearly every variable (apart from race) decreased the RR estimates for severe life threatening asthma. The greatest reductions in the RR estimate occurred when controlling for markers of severity, but these variables were not available for all subjects. In particular, data on arterial $\mathrm{PaCO}_{2}$ were available for only $36 \%$ and data on compliance in only $24 \%$ of the records. This issue was addressed in two ways: (1) by including in the analysis all variables and excluding records with missing data, and (2) by excluding variables which had missing data. The specific confounding variables included in the final analysis were selected from the change in estimate criterion and stepwise procedures (both procedures yielding virtually identical results). Stepwise selection procedures using all variables as potential confounding variables controlling for admission in the past year, any oral steroid (tapering or continuous) course, and physician assessment of severity of previous acute attack yielded $R R=0.90$ (95\% CI 0.41 to 2.0 ). To gauge the potential impact of incomplete data for severity markers, the markers of clinical severity for which $17-35 \%$ of the person time was coded as missing were removed. Stepwise procedures on this limited data set controlled for the number of previous admissions during the study period, admissions in the past year, and any oral steroid (tapering or continuous) course, and produced an RR of $1.2(95 \%$ CI 0.82 to 1.9 ). This procedure eliminates the problem of missing data but also prevents us from controlling for severity markers that appear to be related to both fenoterol and severe life threatening asthma but for which in- 
Table 5 Unadjusted rates and rate ratio $(R R)$ estimates for severe life threatening asthma (SLTA) and death: comparison of inhaled $\beta$ agonist type with inhaled salbutamol

\begin{tabular}{lccccc}
\hline Inhaled $\beta$ agonist & SLTA/death & Person years & Rate* & $R R$ & (95\% CI) \\
\hline None & 3 & 47 & 64 & 1.3 & (0.3 to 3.7) \\
Salbutamol & 49 & 985 & 50 & 1.0 & \\
Fenoterol & 43 & 417 & 103 & 2.1 & $(1.4$ to 3.1) \\
$\quad$ Fenoterol $(200 \mu \mathrm{g})$ & 33 & 346 & 95 & 1.9 & $(1.2$ to 3.0$)$ \\
Fenoterol $(100 \mu \mathrm{g})+$ & 10 & 71 & 141 & 2.8 & $(1.4$ to 5.1) \\
ipratropium & & & & & \\
Fenoterol and salbutamol & 2 & 31 & 65 & 1.3 & $(0.2$ to 4.5$)$ \\
Other/missing & 8 & 91 & 88 & 1.8 & $(0.8$ to 3.6) \\
\hline
\end{tabular}

* Rate per 1000 person years.

formation is unavailable for a sizeable portion of person time.

The unadjusted incidence of severe life threatening asthma by use of inhaled $\beta$ agonists is shown in table 5 . Compared with inhaled salbutamol, the RR estimate for fenoterol is 2.1 (95\% CI 1.4 to 3.1). Users of fenoterol in its high dose formulation $(200 \mu \mathrm{g} /$ inhalation) have a lower $R R$ estimate $(R R=1.9,95 \%$ CI 1.2 to 3.1) than users of low dose fenoterol $(100 \mu \mathrm{g} /$ inhalation $)$ in combination with ipratropium $(R R=2.8,95 \% \mathrm{CI} 1.4$ to 5.4$)$ when compared with inhaled salbutamol. Use of both fenoterol and salbutamol is associated with a rate of severe life threatening asthma similar to the rate among non-users of inhaled $\beta$ agonists $(R R=1.3)$, though data are sparse in each of these categories. A direct comparison of high dose fenoterol with low dose fenoterol in combination with ipratropium indicates that, before adjusting for baseline asthma severity, the low dose formulation tends to be associated with a greater risk of severe life threatening asthma $(\mathrm{RR}=1.5,95 \% \mathrm{CI} 0.73$ to 3.0$)$. However, after adjusting for the number of prior hospital admissions, the difference between these two formulations in the rate of severe life threatening asthma disappears $(R R=0.85,95 \% \mathrm{CI}$ 0.40 to 1.7 ).

A limitation of this study as well as previous non-randomised studies of $\beta_{2}$ agonists is the difficulty in controlling for the effects of asthma severity. To illustrate the difficulty of controlling confounding by severity, table 6 shows the data for the incidence of severe life threatening asthma for patients who used either fenoterol or salbutamol metered dose inhaler (and no other inhaled $\beta$ agonist), stratified by the number of prior hospital admissions. Severe life threatening asthma tends to occur among a small subgroup of patients with especially severe disease. While $84 \%$ of the person time is contributed by people without multiple admissions, $61 \%$ of the severe life threatening asthma attacks occur among people with multiple admissions. Among subgroups with in- creasing severity there is no apparent trend in $R R$ estimates when comparing users of fenoterol metered dose inhalers with salbutamol metered dose inhalers: among patients with no prior admissions $\mathrm{RR}=2.0$, (95\% CI 0.51 to 6.9), for one admission $\mathrm{RR}=0.88$ (95\% CI 0.36 to 2.0 ), and for multiple admissions $R R=$ 1.54 (95\% CI 0.90 to 2.65). After adjusting for differences in the number of hospital admissions between users of fenoterol and users of salbutamol, the RR declines from 2.08 (95\% CI 1.4 to 3.1 ) to 1.36 (95\% CI 0.9 to 2.1 ).

With one or two exceptions, hospitalised patients were discharged on the same inhaled $\beta$ agonist they were using on admission. In examining drug switching between visits - that is, from one discharge to the next admission of the patients discharged on fenoterol $7 \%$ had salbutamol added by the next visit but, on the other hand, among those using salbutamol only, $11 \%$ reported having fenoterol added. Patients on salbutamol were therefore 1.6 (95\% CI 0.98 to 3.0) times more likely to have fenoterol added between visits than vice versa.

\section{Discussion}

This study confirms previous research showing that, before adjusting for baseline risk, inhaled fenoterol is associated with an increased risk of severe life threatening asthma compared with inhaled salbutamol (RR 2.1), and that adjustment for a hospital admission in the past year and any use of oral corticosteroids at the time of the previous attendance reduces the association for inhaled fenoterol (RR 1.5) but does not eliminate it. ${ }^{2-40}$ The initial analysis of the Saskatchewan study found that the RR estimate for fenoterol increased after adjustment for asthma severity, ${ }^{16}$ but after a more appropriate statistical model was employed in the analysis the effect estimate for fenoterol declined markedly. ${ }^{4}$ The results reported here differ from previous work in that, after taking into account additional or more specific detailed classification of risk factors including acute severity at the previous hospital visit (as measured by an inability to speak), race, use of continuous oral corticosteroids at the previous hospital visit (as opposed to any use), and the total number of previous admissions during the study (as opposed to admissions in the past year), inhaled fenoterol was not associated with an increased risk of severe life threatening asthma. The association between inhaled fenoterol and severe life threatening asthma in this study therefore appears to be explained by

Table 6 Incidence of severe life threatening asthma (SLTA)/death according to inhaled $\beta$ agonist type and prior hospital admissions

\begin{tabular}{|c|c|c|c|c|c|c|c|c|}
\hline & \multicolumn{8}{|c|}{ Prior hospital admissions } \\
\hline & \multicolumn{2}{|l|}{0} & \multicolumn{2}{|l|}{1} & \multicolumn{2}{|l|}{$2+$} & \multicolumn{2}{|l|}{ Total } \\
\hline & Fenoterol & Salbutamol & Fenoterol & Salbutamol & Fenoterol & Salbutamol & Fenoterol & Salbutamol \\
\hline $\begin{array}{l}\text { SLTA } \\
\text { Person years } \\
\text { Rate (per } 1000 \text { person years) } \\
\text { Unadjusted rate ratio }(95 \% \mathrm{CI}) \\
\text { Adjusted rate ratio }(95 \% \mathrm{CI}) \\
\end{array}$ & $\begin{array}{l}4 \\
148 \\
27 \\
2.00(0.5\end{array}$ & $\begin{array}{r}7 \\
518 \\
14 \\
\text { to } 6.90)\end{array}$ & $\begin{array}{r}8 \\
185 \\
43 \\
0.88 \\
(0.3\end{array}$ & $\begin{array}{r}18 \\
368 \\
49 \\
\text { to } 2.00)\end{array}$ & $\begin{array}{l}31 \\
84 \\
369 \\
1.54(0.9\end{array}$ & $\begin{array}{l}24 \\
100 \\
240 \\
\text { to } 2.65 \text { ) }\end{array}$ & & \\
\hline
\end{tabular}


fenoterol being prescribed preferentially to patients with severe asthma.

Confounding bias could arise only if variables that were related to the risk of severe life threatening asthma independently from fenoterol were also strongly related to the likelihood of being prescribed fenoterol. We found that use of oral corticosteroids (particularly continuous use) and previous hospital admissions (particularly multiple admissions) are associated not only with an increased risk of severe life threatening asthma (table 2), but also with an increased likelihood of being prescribed fenoterol (table 3). This finding supports the contention that fenoterol was channelled to severe patients, as reported previously in the Netherlands ${ }^{17}$ and New Zealand. ${ }^{18} 19$

It could be argued that the reason patients using fenoterol appeared to have more severe asthma is because fenoterol caused the asthma to become more severe. Therefore, by controlling for baseline risk at the time of the previous event (hospital attendance) we were able to assess potential adverse effects of the prescription of fenoterol. In addition, we sought another way of distinguishing whether fenoterol causes severe asthma by a pharmacological effect or whether fenoterol is merely prescribed more often to patients with severe asthma. Fenoterol was marketed in New Zealand in two formulations administered by metered dose inhaler: one formulation containing $200 \mu \mathrm{g} /$ inhalation which was introduced in 1976 and the other containing $100 \mu \mathrm{g} /$ inhalation along with $40 \mu \mathrm{g}$ ipratropium (an anticholinergic known for its excellent safety profile). The newer lower dose formulation of fenoterol plus ipratropium was introduced in 1986, the first year of this study, and was purported to be a better bronchodilator than fenoterol alone owing to its combination of ingredients. If fenoterol causes severe asthma, then fenoterol administered in higher doses ought to be associated with a greater risk of severe life threatening asthma. On the other hand, if fenoterol was associated with severe life threatening asthma because of preferential prescribing - that is, confounding by severity the lower dose formulation would be prescribed more often to patients whose asthma could not be controlled by existing medications. According to this hypothesis, the low dose formulation which was introduced at a later date would be associated with severe life threatening asthma even more strongly than the high dose formulation.

The rate of severe life threatening asthma among users of the low dose formulation of fenoterol was $141 / 1000$ person years (table 5), and the rate among users of the high dose formulation was $95 / 1000$ person years $(R R=$ $1.5,95 \%$ CI 0.7 to 3.0 ). Although somewhat imprecise, the higher rate of severe life threatening asthma among patients using the lower dose formulation is inconsistent with fenoterol alone having an adverse effect. Instead, this result is consistent with the new low dose formulation being prescribed preferentially to more severe patients. Although only $10 \%$ of our cohort was prescribed the low dose for- mulation of fenoterol during the study period, we were able to control for confounding by the number of previous hospital admissions. After controlling for this severity marker there was little if any difference in the rate of severe life threatening asthma between the two formulations of fenoterol $(R R=0.85,95 \%$ CI 0.4 to 1.7). Consequently, these results do not support a pharmacological effect of fenoterol but, instead, appear to reflect different prescribing patterns according to the severity of the patient's illness.

Fenoterol could have a different effect on asthma death than it has on admissions to the intensive care unit for asthma. It has been postulated that overuse of fenoterol during an attack of asthma severe enough to cause hypoxia may be associated with an increased risk of cardiac arrhythmia when compared with the more $\beta_{2}$ selective inhalers such as salbutamol and terbutaline. ${ }^{20}$ Although it would have been ideal to analyse deaths and admissions to the intensive care unit separately, there were insufficient deaths to conduct conditional analyses that controlled for confounding. However, the unadjusted effect estimates for deaths and admissions to the intensive care unit were very similar. In addition, the researchers who conducted the first study of fenoterol and asthma death have recently reported that fenoterol is also associated with an approximate doubling in the risk of admission to the intensive care unit $(R R=2.0,95 \% \mathrm{CI} 1.4$ to 3.0 ), and that the $R R$ estimate declined slightly after adjusting for a hospital admission in the past year, any oral corticosteroid use at the time of the previous admission, and oral theophylline $(R R=$ $1.8,95 \%$ CI 1.2 to 2.6$).{ }^{10}$ These results support previous findings of our research group that patients with an admission to the intensive care unit are similar both clinically and demographically to those who die, ${ }^{11}$ and that patients who have had a near fatal attack are a group defined as being at high risk of subsequent death. ${ }^{21}$ Thus, the association with fenoterol appears to be essentially the same for asthma death and life threatening asthma.

Despite the availability of much improved data on asthma severity when compared with previous studies, asthma severity and other risk factors for severe life threatening asthma could be measured more accurately than was possible here. It would be desirable to obtain periodic objective measures of lung function, symptom frequency, and bronchial reactivity and to define psychosocial and economic factors more accurately. In this study psychosocial factors were not associated with death or near death, $\mathrm{RR}=1.0$ (95\% CI 0.5 to 1.8 ), but these factors were not specifically requested as part of the emergency department record and have been shown in a prospective study on severe life threatening asthma to be recorded poorly in hospital records. ${ }^{22}$ In addition, we were unable to use all of the severity markers that were available in this study because extensive stratification leads inevitably to sparse data. After conditioning the analyses on multiple severity markers, the random error introduced owing to sparse data ultimately exceeds the confounding 
bias removed through stratification. ${ }^{13}$ Although we exhausted the extent to which confounding could be controlled given the data available, residual confounding may remain. If so, correcting for this possible bias would tend to further decrease the RR estimate for fenoterol, ${ }^{7}$ and may even reduce the RR to less than 1 .

To investigate possible drug switching we looked for changes in inhaled $\beta$ agonist by type reported at sequential hospital visits and found that patients using salbutamol metered dose inhalers were 1.6 (95\% CI 0.98 to 3.0$)$ times more likely to have had fenoterol added than vice versa. The choice of inhaled $\beta$ agonist therefore appeared to lie with the primary care physician and occurred out of hospital, as has been reported elsewhere, ${ }^{23}$ rather than as a result of admission to hospital where there was no evidence that patients were preferentially changed to fenoterol, which has also been reported elsewhere. ${ }^{23}$ Although some changes in treatment probably went undetected, that which occurred was probably small and the bias from misclassification by defining exposure to inhaled $\beta$ agonist at the time of previous discharge is likely to be small. Perhaps a more important source of error in classifying drug use concerns the lack of data on actual use of prescribed medications. Although we sought the physician assessment of global compliance, we do not know how often patients used their medications or if they used them properly. If proper use of medications is similar for different types of $\beta$ agonists, the bias would tend to reduce the magnitude of the observed associations. In this instance the bias is difficult to assess, however, because fenoterol users have more severe asthma and could be less (or more) compliant than patients using salbutamol.

Finally, some occurrences of life threatening asthma could have been missed if hospital records or national mortality data were incomplete or inaccurate. By using National Health Statistics data and databases maintained by the Regional Auckland Area Health Board we were able to access patient details from hospitals other than Middlemore Hospital and where our cohort was defined. This was not carried out in previous New Zealand studies investigating the relationship between fenoterol and death, ${ }^{1-3}$ and may explain why hospital admissions in the previous year appeared a more robust measure of risk in our study than in earlier studies ( $18 \%$ of our cohort had admission to hospitals other than Middlemore Hospital during the study period). Although we cannot quantify the magnitude of such errors, whenever possible we used multiple sources of data, each of which incorporates safeguards to ensure that the data are complete.

In conclusion, this study enhances existing data by following a complete cohort of patients with confirmed asthma and obtaining in- formation on aspects of drug use and asthma severity that were not available in previous studies. These additional data enable previously unmeasured differences in asthma severity to be identified and controlled.

The results indicate that, after taking into account preferential prescribing of fenoterol to patients with severe asthma, fenoterol does not increase the risk of life threatening asthma.

The authors gratefully acknowledge Brenda Birmann for her assistance in processing, reviewing and analysing the data, and Jill Mercer, David McKenzie and Susan Vueglar for data extraction and data entry. We would also like to thank the Middlemore Hospital Emergency Department staff for allowing Middlemore Hospital Emergency Department staff for allowing
access to their medical records and Dr P Rodwell and Dr A access to their medical records and Dr P Rodwell and Dr A
Veale in particular who were instrumental in establishing the triplicated asthma management forms. This study was supported by the Asthma Foundation of New Zealand and a grantin-aid from Boehringer Ingelheim Ltd towards the data analysis.

1 Crane J, Pearce N, Flatt A, Burgess C, Jackson R, Kwong $\mathrm{T}$, et al. Prescribed fenoterol and death from asthma in New Zealand, 1981-83: case-control study. Lancet 1989; i:917-22.

2 Rea HH. Fenoterol and fatal asthma (letter). NZ Med $\mathcal{f}$ 1989;302:356-7.

3 Grainger J, Woodman K, Pearce N, Crane J, Burgess C, Keane A, et al. Prescribed fenoterol and death from asthma in New Zealand, 1981-7: a further case-control study. Thorax 1991;46:105-11.

4 Pearce N, Crane J, Beasley R, Burgess C, Jackson R. Prescribed fenoterol and death from asthma in New Zealand, 1981-7: a further case-control study (letter). Thorax 1992; 1981-7:

5 Suissa S, Ernst P, Boivin JF, Horwitz RI, Habbick B, Cockroft $\mathrm{D}$, et al. A cohort analysis of excess mortality in asthma and the use of $\beta$-agonists. Am $\mathcal{F}$ Respir Crit Care Med 1994;149:604-10.

6 Lanes SF, Poole C, Walker A. Prescribed fenoterol and death from asthma in New Zealand, 1981-7: a further case-control study (letter). Thorax 1992;47:574.

7 Brenner H. Bias due to non-differential misclassification of polytomous confounders. F Clin Epidemiol 1993;46:57-63.

$8 \mathrm{Garrett} \mathrm{J}$. Baseline risk for asthma death (letter). NZ Med f 1992;105:319.

9 Pearce N, Grainger J, Atkinson M, Crane J, Burgess C, Windom $\mathrm{H}$, et al. Case control study of prescribed fenoterol and death from asthma in New Zealand 1977-81. Thorax 1990;45:170-5.

10 Burgess C, Pearce N, Thiruchelvan R, Wilkinson R, Linaker $\mathrm{C}$, Woodman $\mathrm{K}$, et al. Prescribed drug therapy and nearfatal asthma attacks. Eur Respir 7 1994;7:498-503.

11 Richards GN, Kolbe J, Fenwick J, Rea HH. Demographic characteristics of patients with severe life threatening asthma: a comparison with asthma deaths. Thorax 1993; 48:1105-9.

12 Rothman KJ. Modern epidemiology. Boston: Little, Brown and Company, 1986:64.

13 Greenland S. Modeling and variable selection in epidemiologic analysis. Am $\mathcal{f}$ Publ Health 1989;79:340-9.

14 Garrett JE, Mulder J, Wong-Toi H. Reasons for racial differences in $\mathrm{A} \& \mathrm{E}$ attendance rates for asthma. NZ Med f 1989;102:121-4.

15 Garrett JE, Mulder J, Wong Toi H. Characteristics of asthmatics using an urban accident and emergency department. NZ Med f 1988;101:359-61.

16 Spitzer WO, Suissa S, Ernst P, Horwitz R, Habbick B, Cockroft D, et al. The use of $\beta$-agonists and the risk of death and near death from asthma. $N$ Engl f Med 1992; 326:501-6.

17 Petri $\mathrm{H}$, Urquhart J, Herings $R$, Bakker A. Characteristics of patients prescribed three different inhalational beta-2 agonists: an example of the channeling phenomenon. Post Marketing Surveillance 1991;5:57-66.

18 Garrett JE, Turner P. The severity of asthma in relation to $\beta$-agonist prescribing. NZ Med f 1991;104:39-40

19 Wilson JD. Selective prescribing of fenoterol and salbutamol in New Zealand general practice. Post Marketing Surveillance 1991;5:105-8.

20 Crane J, Burgess C, Pearce N, Beasley R. The $\beta$-agonist controversy: a perspective. Eur Respir Rev 1993;3:475-82.

21 Rea HH, Scragg R, Jackson R, Beaglehole R, Fenwick J, Sutherland DC. Case control study of asthma deaths. Thorax 1986;41:833-9.

22 Kolbe J, Vamos M, Richards G, Garrett J. Differences in asthma self management knowledge and behaviour in acute severe asthma. Chest 1996 (in press).

23 Beasley R, Burgess C, Pearce N, Woodman K, Crane J. Confounding by severity does not explain the association between fenoterol and asthma death. Clin Exp Allergy 1994;24:660-8. 